\title{
Isoform-specific Regulation of Platelet-derived Growth Factor Activity and Binding in Osteoblast-enriched Cultures from Fetal Rat Bone
}

\author{
Michael Centrella, * Thomas L. McCarthy, * William F. Kusmik, ${ }^{*}$ and Emesto Canalis* \\ *Departments of Research and Medicine, Saint Francis Hospital and Medical Center, Hartford, Connecticut 06105; \\ and University of Connecticut School of Medicine, Farmington, Connecticut 06030; \\ and ${ }^{\ddagger}$ Department of Cell Biology, Creative BioMolecules, Hopkinton, Massachusetts 01748
}

\begin{abstract}
In osteoblast-enriched cultures from fetal rat bone, the A-chain homodimer of platelet-derived growth factor (PDGF-AA) is less potent than the PDGF isoforms containing $B$ chain subunits (PDGF-AB and PDGF-BB), but normal osteoblasts appear to synthesize only PDGF-A subunit mRNA and polypeptide. However, other agents may regulate PDGF-AA activity in skeletal tissue. Pretreatment of osteoblast-enriched cultures with interleukin $1 \alpha$ (IL-1 $\alpha$ ) or tumor necrosis factor- $\alpha$ (TNF- $\alpha$ ) synergistically enhanced the mitogenic effect of PDGF-AA coincident with increased binding site occupancy, but neither factor augmented PDGF-BB activity or binding. Polyacrylamide gel analysis showed ${ }^{125}$ I-PDGF-AA binding complexes predominantly at $>200 \mathrm{kD}$ and faint labeling at $185 \mathrm{kD}$. After IL-1 $\alpha$ or TNF- $\alpha$ pretreatment, PDGF-AA binding increased at both sites, but this effect was more striking at $185 \mathrm{kD}$, which co-migrated with ${ }^{125}$ I-PDGF-BB-labeled complexes. PDGF-AA binding sites were rapidly lost by comparison to those for PDGF-BB in cycloheximide-treated cultures, but they remained relatively enhanced by IL-1 $\alpha$ and TNF- $\alpha$ pretreatment. These studies indicate that IL- $\alpha$ and TNF- $\alpha$ increase PDGFAA binding and activity for osteoblasts by mechanisms that are at least in part independent of new receptor synthesis, and suggest regulatory events that could control how PDGF binding sites specifically recognize different ligands. (J. Clin. Invest. 1992. 89:1076-1084.) Key words: interleukin 1 - mitogens • receptor turnover $\bullet$ transforming growth factor- $\beta$ - tumor necrosis factor
\end{abstract}

\section{Introduction}

Platelet-derived growth factor (PDGF) ${ }^{1}$ is a polypeptide dimer comprising either PDGF-A or PDGF-B subunits, and is pro-

These studies were presented in part at the 12th and 13th Annual Meetings of the American Society for Bone and Mineral Research (Atlanta, GA, 1990; San Diego, CA, 1991), and the 30th Annual Meeting of the American Society for Cell Biology (San Diego, CA, 1990).

Address reprint requests to Dr. Centrella, Molecular Biology Laboratory, MS 324, Saint Francis Hospital and Medical Center, 114 Woodland Street, Hartford, CT 06105-1299.

Received for publication 31 July 1991 and in revised form 28 October 1991.

1. Abbreviations used in this paper: $\mathrm{BS}^{3}$, bis(sulfosuccinimidyl) suberate; DSS, disuccinimidyl suberate; PDGF, platelet-derived growth factor; TGF, transforming growth factor; TNF, tumor necrosis factor.

J. Clin. Invest.

(C) The American Society for Clinical Investigation, Inc.

0021-9738/92/04/1076/09 \$2.00

Volume 89, April 1992, 1076-1084 duced in a variety of tissues where it acts as a local mitogen (1-6). In many tissue systems, including osteoblast-enriched cultures from fetal rat bone, the biochemical effects of each dimer (PDGF-AA, PDGF-AB, PDGF-BB) are graded with regard to PDGF-B subunit content, with PDGF-BB being the most stimulatory (7-11). This occurs at least in part by $(a)$ the existence of two binding sites, termed PDGF- $\alpha$ and PDGF- $\beta$ receptor subunits, $(b)$ inefficient binding by PDGF-AA to $\beta$ receptor subunits, and $(c)$ the likelihood that $\beta$ receptor subunit occupancy permits optimal PDGF-mediated biological effects $(8,10-15)$.

In some cell systems, notably cultured murine fibroblasts, preexposure to PDGF enhances the mitogenic effect of certain so-called progression factors $(16,17)$. In osteoblast-enriched cultures from fetal rat bone, PDGF isoforms containing B subunits (PDGF-BB and PDGF-AB) induce potent increases in cell replication without the addition of other agents $(11,18)$. In addition, several lines of evidence suggest that normal osteoblasts produce only PDGF-A subunit transcripts and polypeptide $(6,19)$, but exhibit a limited response to PDGF-AA (11). Consequently, osteoblasts might require a second agent, produced by cells beyond their lineage, in order to increase the effectiveness of PDGF-AA in bone.

Macrophages are prominent at the sites of inflammation after fracture and during the "reversal" phase of remodeling before new bone formation (20). Activated macrophages store and release a number of growth regulators (21-24), and these agents could be involved in the local control of osteoblast activity. Among the well-described macrophage products are interleukin $1 \alpha$ (IL-1 $\alpha$ ), tumor necrosis factor- $\alpha$ (TNF- $\alpha$ ), and transforming growth factor- $\beta$ (TGF- $\beta$ ) (22-24). Of these, TGF- $\beta$ induces potent effects on replication and differentiated function in a variety of in vitro and in vivo models used to study bone metabolism (25-29). IL- $\alpha$ and TNF- $\alpha$ also regulate a number of biochemical processes involved in bone remodeling in intact bone organ cultures (30-33). By themselves, IL-1 $\alpha$ and TNF- $\alpha$ induce limited effects in osteoblast-enriched cultures from fetal rat bone $(34,35)$, suggesting that some activities regulated by these agents in the intact tissue could result from interactions with other factors produced locally in bone. In this regard, an interdependency between IL- $1 \alpha$ or TNF- $\alpha$ and PDGF-AA, by way of alterations in IL- $1 \alpha$ binding or PDGF-AA synthesis, has been reported previously in other tissue systems $(4,36,37)$.

The present studies were therefore performed to assess the possibility that the modest activity of PDGF-AA in bone cell cultures could be enhanced by macrophage-derived products, and to determine if these factors could do so by modifying PDGF-AA receptor binding. Regulatory effects of these sorts could be important to increase in a selective manner the anabolic function of locally produced PDGF-AA during fracture repair or normal bone remodeling. 


\section{Methods}

Cell cultures. Parietal bones from 22-d-old fetuses (taken from timedpregnant Sprague-Dawley rats, Charles River Breeding Laboratories, Wilmington, MA) were dissected free of sutures and subjected to five sequential collagenase digestions. While overlap among cells at various stages of differentiation may occur, the populations released during the last three collagenase treatments are enriched with cells exhibiting osteoblast characteristics $(38,39)$. Cells from a pool of populations 3-5 were plated at 6,250 cells $/ \mathrm{cm}^{2}$ in Dulbecco's modified Eagle's medium containing $20 \mathrm{mM}$ of Hepes buffer, $\mathrm{pH} 7.2,100 \mu \mathrm{g} / \mathrm{ml}$ ascorbic acid, penicillin and streptomycin, and $10 \%$ fetal bovine serum (FBS; all from Gibco, Grand Island, NY). The cultures were maintained without medium change until reaching confluence $\left(\sim 50,000\right.$ cells $\left./ \mathrm{cm}^{2}\right)$. At confluence the cultures were refed with identical medium lacking only serum, in the absence or presence of vehicle or test agents, and for the times indicated. All experiments were performed with primary cultures.

Cell replication. To measure cell replication, PDGF-AA or PDGFBB were added in serum-free medium after a 20 -h pretreatment with vehicle or individual test agents, and the cultures were incubated for an additional 23-h period. DNA synthesis was measured by pulse-labeling cultures with $5 \mu \mathrm{Ci} / \mathrm{ml}\left[{ }^{3} \mathrm{H}\right.$-methyl]thymidine $(80 \mathrm{Ci} / \mathrm{mmol}$; Dupont New England Nuclear, Boston, MA) during the last $2 \mathrm{~h}$ of treatment. $\left[{ }^{3} \mathrm{H}\right]$ thymidine incorporation into DNA was determined by lysing the cells in $0.1 \mathrm{M}$ sodium dodecylsulfate and $0.1 \mathrm{~N}$ sodium hydroxide, collecting the insoluble material formed by precipitation with $10 \%$ trichloroacetic acid, and scintillation counting. Data are shown as the total amount of acid insoluble $\left[{ }^{3} \mathrm{H}\right]$ thymidine incorporated per culture well. DNA content was assessed by fluorometry $(11,25,40)$.

Binding studies. To examine PDGF binding, cultures were pretreated with vehicle or with test agents at the concentrations shown or for the times indicated, and then incubated in serum-free medium supplemented with $4 \mathrm{mg} / \mathrm{ml}$ bovine serum albumin (BSA; Sigma Chemical Co., St. Louis, MO) and either ${ }^{125}$ I-PDGF-AA or ${ }^{125}$ I-PDGF-BB for $3 \mathrm{~h}$ at $4^{\circ} \mathrm{C}$. For Scatchard analysis, cultures were incubated with labeled ligand without or with increasing amounts of homologous unlabeled ligands to achieve saturation. Nonspecific binding (in the range of $6-18 \%$ of total binding; 11,18 ), determined in the presence of 100 -fold molar excess unlabeled PDGF-AA or PDGF-BB, was subtracted to calculate specific binding. Binding site turnover was determined by the inclusion of $2 \mu \mathrm{M}$ cycloheximide or $1.3 \mu \mathrm{M} \alpha$-amanitin during the pretreatment period. For dose response, time course, Scatchard analysis, and binding site turnover studies, the samples were rinsed and extracted as described previously $(11,18)$, and the amounts of bound radioligand were measured in a gamma spectrometer. To visualize ${ }^{125} \mathrm{I}-$ PDGF-AA and ${ }^{125}$ I-PDGF-BB binding complexes, cultures were rinsed with chilled binding medium, cross-linked with $0.1 \mathrm{mM}$ disuccinimidyl suberate (DSS), extracted with sample buffer (41), and fractionated by electrophoresis on a 5-15\% linear gradient polyacrylamide gel. Bound ${ }^{125}$ I-labeled complexes were visualized by autoradiography as previously reported $(11,18)$.

Test agents. All unlabeled PDGF preparations (each purified to greater than $98 \%$ purity) used in these studies were recombinant human molecules produced by Creative Biomolecules, as described previously (11). In these studies the recombinant PDGF-BB preparation contained amino acid substitutions in positions 1 (serine $\rightarrow$ alanine) and 12 (methionine $\rightarrow$ valine), which did not alter mitogenic activity (11). Purified human IL-1 $\alpha$ was provided by Hoffmann-LaRoche, Inc., Nutley, NJ. Recombinant murine TNF- $\alpha$ and recombinant human TGF- $\beta 1$ were provided by Genentech, Inc., S. San Francisco, CA. Recombinant human insulin-like growth factor I was provided by Eli Lilly \& Co., Indianapolis, IN. All growth factors were dissolved in $0.05 \mathrm{M}$ $\mathrm{HCl}$ containing $4 \mathrm{mg} / \mathrm{ml}$ BSA to obtain concentrations of $300-800 \mathrm{nM}$ before use. In control experiments, concentrations of vehicle equivalent to the levels achieved by the highest growth factor concentrations tested had no activity in the cell culture assays. ${ }^{125}$ I-PDGF-AA (560$4,500 \mathrm{Ci} / \mathrm{mmol})$ and ${ }^{125} \mathrm{I}-\mathrm{PDGF}-\mathrm{BB}(1,140-4,500 \mathrm{Ci} / \mathrm{mmol})$ were ob- tained from Biomedical Technologies, Inc., Stoughton, MA, or Creative BioMolecules. ${ }^{125}$ I-PDGF-BB from Creative BioMolecules utilized a recombinant PDGF-BB preparation synthesized to include a 10-amino acid amino terminal extension containing a single tyrosine residue to facilitate iodination, as described previously $(11,18)$. Cycloheximide, $\alpha$-amanitin, amino-terminal rat parathyroid hormone fragment 1-34 (PTH), and lipopolysaccharide (LPS) were obtained from Sigma. DSS and bis(sulfosuccinimidyl) suberate $\left(\mathrm{BS}^{3}\right)$ were obtained from Pierce Chemical Co., Rockford, IL.

Statistical methods. Results from proliferation studies were assessed by analysis of variance, with limits set by the Bonferroni or Dunnet procedures, and are reported as mean \pm SE. Experiments to evaluate changes in ligand binding contained duplicate or triplicate samples per group. The data from these studies are reported as mean $\pm S D$ with duplicate samples, or as mean \pm SE with triplicate samples, and are representative of two or more analogous studies.

\section{Results}

Comparable to earlier studies (11), after $23 \mathrm{~h}$ of treatment with PDGF-AA at 0.3-3 nM, DNA synthesis rates were enhanced two- to threefold in serum-deprived osteoblast-enriched cultures from fetal rat parietal bone. The effect of PDGF-AA was near-maximal at 1-3 nM, whereas PDGF-BB at 0.1-3 nM increased DNA synthesis rates two- to eightfold. When the cultures were exposed to IL- $1 \alpha$ at $0.6-6 \mathrm{nM}$ for the 20-h serum deprivation interval and then supplemented with control medium, only a marginal 0.4 -fold increase in the basal rate of DNA synthesis was achieved. However, if the IL- $1 \alpha$-pretreated cultures were subsequently supplemented with PDGF-AA, there was a synergistic increase in DNA synthesis to essentially the level produced by PDGF-BB alone. The effect was dose dependent with regard to IL- $1 \alpha$, inducing PDGF-BB-like increases at $\sim 6 \mathrm{nM}$. Parallel studies with PDGF-BB did not reveal a corresponding synergy between any concentrations of IL- $1 \alpha$ or PDGF-BB examined (Fig. 1). Similarly, IL- $1 \alpha$ pretreatment enhanced total DNA content in cultures supplemented with PDGF-AA, but did not modify the amount of DNA produced in cultures treated with PDGF-BB (Table I).

Analogous studies were performed after TNF- $\alpha$ pretreatment. Earlier work in this culture model demonstrated that, relative to several other growth regulators, TNF- $\alpha$ by itself produces only moderate increases in DNA synthesis rates $(34,42)$, and its effect was somewhat less pronounced $(\sim 2.5$-fold) after the additional 23-h culture interval used in the present studies. Nevertheless, similar to IL- $1 \alpha$, pretreatment with TNF- $\alpha$ at 0.6-6 nM specifically enhanced the mitogenic effect of PDGFAA. Synergy was observed between $0.3 \mathrm{nM}$ PDGF-AA and $0.6-6 \mathrm{nM}$ TNF- $\alpha$, but the combined effects of $0.3 \mathrm{nM}$ PDGFBB and TNF- $\alpha$ were less than additive (Table II, experiment 1). Even at a PDGF-AA concentration of $1 \mathrm{nM}$, which is nearmaximal in unpretreated cultures, its effectiveness was increased synergistically in TNF- $\alpha$-pretreated cultures, whereas the stimulatory effect of $1 \mathrm{nM}$ PDGF-BB was inhibited by TNF- $\alpha$ pretreatment (Table II, experiment 2).

In contrast to results with IL- $1 \alpha$ and TNF- $\alpha$, pretreatment of the osteoblast-enriched cultures with TGF- $\beta 1$ did not produce analogous changes in the mitogenic effects of PDGF-AA or PDGF-BB (Table II, experiment 3). Pretreatment with other growth regulators such as IGF-I, PTH, and LPS was also ineffective in this regard (not shown).

Since PDGF-AA binding is relatively inefficient in these cultures by comparison to PDGF-BB (11), the altered response 


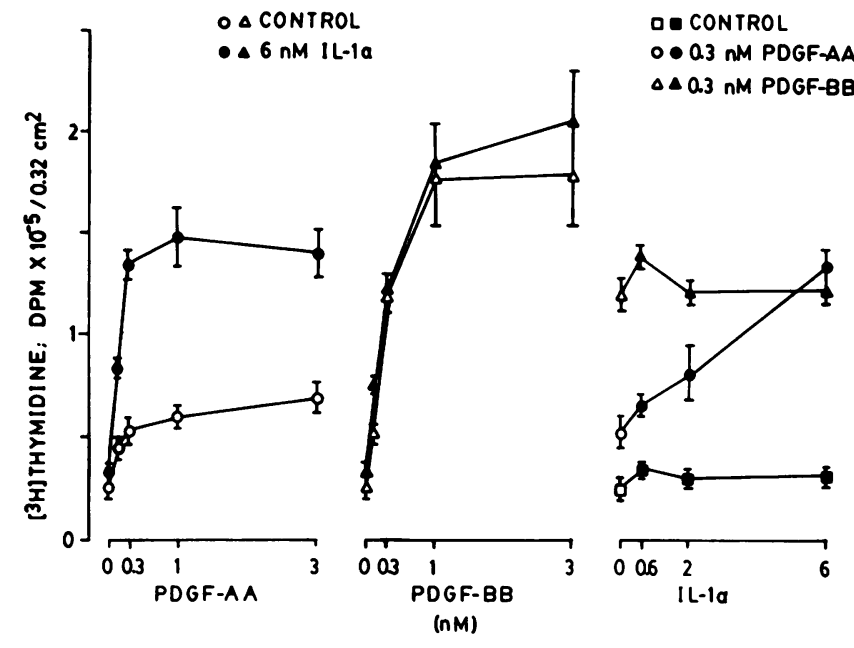

Figure 1. Effect of IL-1 $\alpha$ pretreatment on DNA synthesis in osteoblast-enriched cultures from fetal rat bone subsequently stimulated by PDGF-AA or PDGF-BB. Serum-deprived confluent cell cultures were incubated for $20 \mathrm{~h}$ without or with IL- $1 \alpha$, and then treated with control medium, PDGF-AA, or PDGF-BB for the next 23-h interval. DNA synthesis was measured by pulse-labeling with $\left[{ }^{3} \mathrm{H}\right]$ thymidine for the last $2 \mathrm{~h}$ of culture as described in Methods. Data are shown as $\mathrm{dpm} \times 10^{-4} /$ culture, and are given as mean $\pm \mathrm{SE}$ of four replicate $0.32-\mathrm{cm}^{2}$ culture wells per condition. Similar results were obtained in three separate experiments. In the absence of IL- $1 \alpha$, PDGF-AA at 3 $\mathrm{nM}$ or PDGF-BB at $0.3-3 \mathrm{nM}$ significantly enhanced DNA synthesis $(P<0.05)$. The combined effect of pretreatment with $6 \mathrm{nM} \mathrm{IL-1} \alpha$ and treatment with 0.3-3 nM PDGF-AA, but not PDGF-BB, was significantly different from that by either factor alone $(P<0.01)$.

to PDGF-AA could have resulted from a differential increase in its binding capacity. This was examined by measuring PDGF-AA and PDGF-BB binding after pretreatment with IL$1 \alpha$ or TNF- $\alpha$. Increases in PDGF-AA binding were detected within $4 \mathrm{~h}$ of pretreatment with either factor and continued to

Table I. Effect of Pretreatment with IL-1 $\alpha$ on DNA Content in Osteoblast-enriched Cultures from Fetal Rat Bone Subsequently Stimulated by PDGF-AA or PDGF-BB

\begin{tabular}{lll}
\hline Pretreatment & \multicolumn{2}{c}{ Treatment } \\
\hline & & $\mu g D N A / 2 \mathrm{~cm}^{2}$ \\
None & None & $1.20 \pm 0.05 \quad(n=7)$ \\
None & PDGF-AA & $1.39 \pm 0.04 \quad(n=8)$ \\
None & PDGF-BB & $2.01 \pm 0.09^{*} \quad(n=8)$ \\
IL-1 $\alpha$ & None & $1.39 \pm 0.03 \quad(n=8)$ \\
IL-1 $\alpha$ & PDGF-AA & $2.00 \pm 0.08^{* \neq}(n=7)$ \\
IL-1 $\alpha$ & PDGF-BB & $2.12 \pm 0.12^{*}(n=8)$
\end{tabular}

Cells were serum-deprived, pretreated with control medium or $6 \mathrm{nM}$ IL- $1 \alpha$ for $20 \mathrm{~h}$, and supplemented with control medium or $1 \mathrm{nM}$ of PDGF-AA or PDGF-BB for $23 \mathrm{~h}$, and DNA content was measured by fluorometry, as described in Methods. Data are given as the mean $\pm \mathrm{SE}$ from two experiments, each containing three or four replicate $2-\mathrm{cm}^{2}$ cultures per condition. The numbers in parentheses indicate the number of samples measured for each condition. * Significant difference from untreated cultures; ${ }^{\ddagger}$ Significant difference from pretreatment or treatment with the same concentration of either factor alone $(P<0.01)$.
Table II. Effects of TNF- $\alpha$ and TGF- $\beta$ Pretreatment on DNA Synthesis in Osteoblast-enriched Cultures from Fetal Rat Bone Subsequently Stimulated by PDGF-AA or PDGF-BB

\begin{tabular}{lccc}
\hline & \multicolumn{3}{c}{ Treatment } \\
\cline { 2 - 4 } Pretreatment & None & PDGF-AA & PDGF-BB \\
\hline & & $d p m \times 10^{-4} /$ culture \\
Experiment 1 & & $(0.3 \mathrm{nM})$ & $(0.3 \mathrm{nM})$ \\
None & $2.6 \pm 0.5$ & $6.1 \pm 0.2^{*}$ & $8.7 \pm 0.3^{*}$ \\
TNF- $\alpha(0.6 \mathrm{nM})$ & $4.7 \pm 0.2$ & $9.3 \pm 0.5^{* \ddagger}$ & $6.7 \pm 0.5^{*}$ \\
TNF- $\alpha(6.0 \mathrm{nM})$ & $5.0 \pm 0.9^{*}$ & $13.1 \pm 1.1^{* \ddagger}$ & $7.1 \pm 0.5^{*}$ \\
Experiment 2 & & $(1.0 \mathrm{nM})$ & $(1.0 \mathrm{nM})$ \\
None & $1.8 \pm 0.1$ & $5.6 \pm 0.4^{*}$ & $16.1 \pm 0.7^{*}$ \\
TNF- $\alpha(0.6 \mathrm{nM})$ & $3.4 \pm 0.3$ & $9.6 \pm 0.6^{* \ddagger}$ & $14.7 \pm 1.5^{*}$ \\
TNF- $\alpha(6.0 \mathrm{nM})$ & $4.8 \pm 0.1^{*}$ & $11.8 \pm 1.1^{* \ddagger}$ & $11.4 \pm 0.7^{* \ddagger}$ \\
Experiment 3 & & $(1.0 \mathrm{nM})$ & $(1.0 \mathrm{nM})$ \\
None & $1.7 \pm 0.2$ & $3.6 \pm 0.7$ & $5.6 \pm 1.0^{*}$ \\
TGF- $\beta(0.004 \mathrm{nM})$ & $1.6 \pm 1.0$ & $3.6 \pm 0.2$ & $6.2 \pm 0.5^{*}$ \\
TGF- $\beta(0.04 \mathrm{nM})$ & $9.5 \pm 0.6^{*}$ & $12.1 \pm 0.7^{*}$ & $9.2 \pm 1.8^{*}$ \\
TGF- $\beta(0.40 \mathrm{nM})$ & $6.5 \pm 0.4^{*}$ & $8.7 \pm 1.3^{*}$ & $5.8 \pm 0.3^{*}$ \\
& & &
\end{tabular}

Serum-deprived confluent cell cultures were incubated for $20 \mathrm{~h}$ without or with TNF- $\alpha$ or TGF- $\beta$, and then treated with unsupplemented medium, PDGF-AA, or PDGF-BB for the next 23-h interval. DNA synthesis was measured by pulse-labeling with $\left[{ }^{3} \mathrm{H}\right]$ thymidine for the last $2 \mathrm{~h}$ of culture as described in Methods. Data are given as mean $\pm \mathrm{SE}$ of four replicate $0.32-\mathrm{cm}^{2}$ culture wells per condition. Similar results were obtained in two or more separate experiments. * Significant difference from untreated cultures; ${ }^{\ddagger}$ significant difference from pretreatment or treatment with the same concentration of either factor alone $(P<0.05)$.

rise at $24 \mathrm{~h}$ (Table III). The effects of IL- $1 \alpha$ and TNF- $\alpha$ were each dose-related (Table IV). Scatchard analysis indicated that a 24-h pretreatment with IL-1 $\alpha$ (Fig. 2) or TNF- $\alpha$ (not shown) produced a nearly twofold increase in PDGF-AA binding capacity without altering its affinity, but neither IL-1 $\alpha$ nor TNF$\alpha$ significantly altered PDGF-BB binding (Fig. 2 and Tables III and IV). Furthermore, the stimulatory effects of IL-1 $\alpha$ and TNF- $\alpha$ were not universal, since pretreatment with TGF- $\beta 1$ specifically decreased PDGF-AA binding without altering PDGF-BB binding in these cultures (Fig. 3 and Table IV). Although there was some variability in the calculated amounts of either PDGF-AA or PDGF-BB binding using different batches of radiolabeled ligand, the relative effects of pretreatment with various agents were consistent throughout the course of these studies.

When the cultures were incubated with either ${ }^{125}$ I-PDGFAA or ${ }^{125}$ I-PDGF-BB, chemically cross-linked, and examined by polyacrylamide gel electrophoresis and autoradiography, different binding profiles were obtained with each radioligand (Fig. 4). Even though its banding pattern was somewhat indistinct, complexes containing ${ }^{125}$ I-PDGF-AA migrated predominantly at $>200 \mathrm{kD}$, with a small degree of binding at $185 \mathrm{kD}$ (lane 1). In contrast, ${ }^{125} \mathrm{I}$-PDGF-BB labeled complexes migrated predominantly at $185 \mathrm{kD}$ (lane 2). Analogous to previously reported cross-competition binding studies in these cultures (11), unlabeled PDGF-AA reduced ${ }^{125}$ I-PDGF-AA binding at these sites and only moderately decreased that by 
Table III. Time-related Effects of IL-1 $\alpha$ and TNF- $\alpha$ on PDGF-AA and PDGF-BB Binding in Osteoblast-enriched Cultures from Fetal Rat Bone

\begin{tabular}{|c|c|c|c|}
\hline Pretreatment & Hours & PDGF-AA & PDGF-BB \\
\hline & & \multicolumn{2}{|c|}{ fmol bound $/ \mathrm{cm}^{2}$} \\
\hline \multirow[t]{4}{*}{ Experiment 1 (IL-1 $\alpha)$} & 0 & $0.48 \pm 0.01$ & $3.2 \pm 0.08$ \\
\hline & 4 & $0.57 \pm 0.01$ & $3.2 \pm 0.09$ \\
\hline & 24 & $0.95 \pm 0.08$ & $3.5 \pm 0.15$ \\
\hline & 48 & $0.91 \pm 0.03$ & $3.4 \pm 0.17$ \\
\hline \multirow[t]{4}{*}{ Experiment 2 (TNF- $\alpha$ ) } & 0 & $0.33 \pm 0.02$ & $2.2 \pm 0.12$ \\
\hline & 4 & $0.47 \pm 0.01$ & $2.1 \pm 0.06$ \\
\hline & 24 & $0.64 \pm 0.02$ & $2.0 \pm 0.04$ \\
\hline & 43 & $0.75 \pm 0.01$ & $2.3 \pm 0.12$ \\
\hline
\end{tabular}

Serum-deprived cultures were incubated for the times shown with 2 nM IL- $1 \alpha$ or TNF- $\alpha$, and subsequently incubated in binding medium supplemented with either ${ }^{125}$ I-PDGF-AA or ${ }^{125}$ I-PDGF-BB for $3 \mathrm{~h}$ at $4^{\circ} \mathrm{C}$. The cultures were rinsed four times with cold buffer, extracted with $1 \%$ Triton X-100, and the amount of bound label was measured in a gamma spectrometer. The data were calculated by reference to culture size $\left(2 \mathrm{~cm}^{2}\right)$ and radioligand concentration $(0.1 \mathrm{nM})$, are given as mean $\pm \mathrm{SE}$ of triplicate samples, and are representative of two separate experiments.

Table IV. Dose-related Effects of IL-1 $\alpha, T N F-\alpha$, and TGF- $\beta$ on PDGF-AA and PDGF-BB binding in Osteoblastenriched Cultures from Fetal Rat Bone

\begin{tabular}{lcc}
\hline \multicolumn{1}{c}{ Pretreatment } & PDGF-AA & PDGF-BB \\
\hline & \multicolumn{2}{c}{ fmol bound $/ \mathrm{cm}^{2}$} \\
Experiment 1 & \\
None & $0.69 \pm 0.03$ & $2.7 \pm 0.17$ \\
IL-1 $\alpha(0.06 \mathrm{nM})$ & $1.08 \pm 0.03$ & $2.7 \pm 0.18$ \\
IL-1 $\alpha(0.6 \mathrm{nM})$ & $1.22 \pm 0.08$ & $2.5 \pm 0.31$ \\
IL-1 $\alpha(6.0 \mathrm{nM})$ & $1.20 \pm 0.02$ & $2.6 \pm 0.09$ \\
Experiment 2 & & \\
None & $0.35 \pm 0.01$ & $1.9 \pm 0.07$ \\
TNF- $\alpha(0.06 \mathrm{nM})$ & $0.46 \pm 0.03$ & $1.8 \pm 0.06$ \\
TNF- $\alpha(0.6 \mathrm{nM})$ & $0.70 \pm 0.02$ & $1.9 \pm 0.04$ \\
TNF- $\alpha(6.0 \mathrm{nM})$ & $0.76 \pm 0.03$ & $2.0 \pm 0.04$ \\
Experiment 3 & & $1.0 \pm 0.02$ \\
None & $0.62 \pm 0.02$ & $0.8 \pm 0.06$ \\
TGF- $\beta(0.004 \mathrm{nM})$ & $0.55 \pm 0.02$ & $0.8 \pm 0.08$ \\
TGF- $\beta(0.04 \mathrm{nM})$ & $0.42 \pm 0.03$ & $0.9 \pm 0.09$ \\
TGF- $\beta(0.4 \mathrm{nM})$ & $0.19 \pm 0.01$ & \\
Experiment 4 & & $0.8 \pm 0.08$ \\
None & $0.53 \pm 0.01$ & $0.8 \pm 0.02$ \\
IL-1 $\alpha(0.6 \mathrm{nM})$ & $0.86 \pm 0.02$ & $0.7 \pm 0.02$ \\
TNF- $\alpha(0.6 \mathrm{nM})$ & $1.04 \pm 0.06$ & $1.0 \pm 0.03$ \\
TGF- $\beta(0.4 \mathrm{nM})$ & $0.16 \pm 0.01$ & \\
\hline & & \\
& &
\end{tabular}

Serum-deprived cultures were pretreated for $20 \mathrm{~h}$ with the concentrations of IL- $1 \alpha$, TNF- $\alpha$, or TGF- $\beta$ shown, and subsequently incubated in binding medium supplemented with either ${ }^{125}$ I-PDGF-AA or ${ }^{125} \mathrm{I}$-PDGF-BB for $3 \mathrm{~h}$ at $4^{\circ} \mathrm{C}$. The cultures were rinsed four times with cold buffer and extracted with detergent, and the amount of bound label was measured in a gamma spectrometer. The data were calculated by reference to culture size (4.8-9.6 $\left.\mathrm{cm}^{2}\right)$ and radioligand concentration $(0.1 \mathrm{nM})$, are the averages and standard deviations of duplicate samples, and are representative of two or more separate experiments.

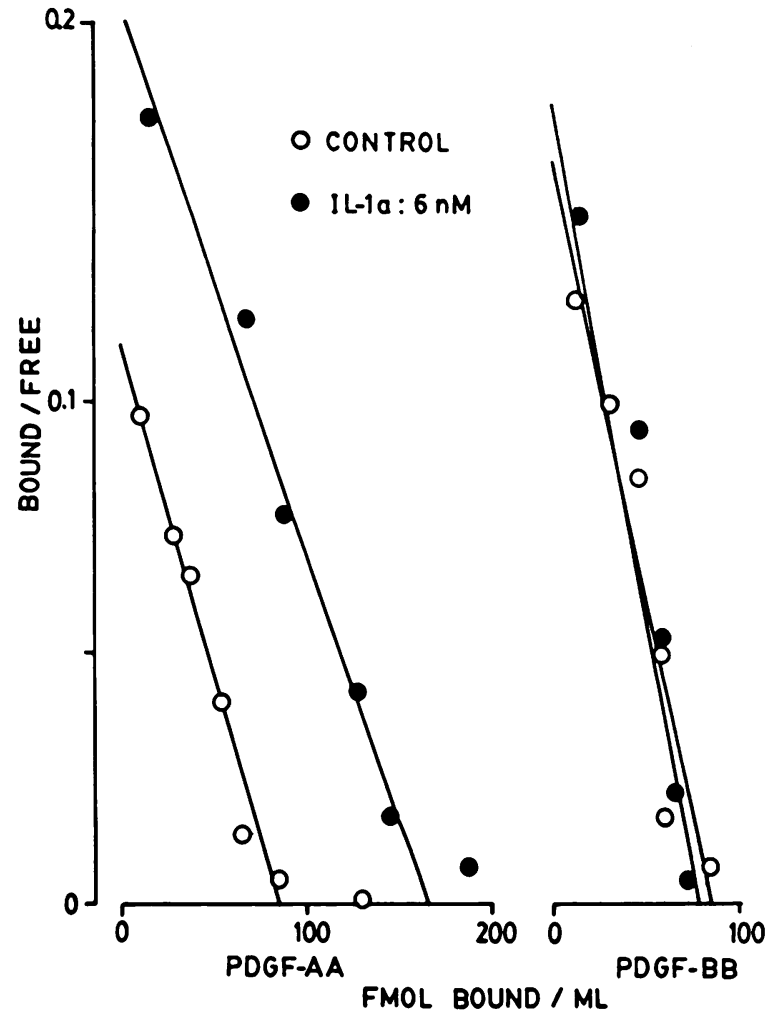

Figure 2. Effect of IL-1 $\alpha$ on PDGF-AA and PDGF-BB binding in osteoblast-enriched cultures from fetal rat bone. Serum-deprived confluent cultures were pretreated for 20 hours with vehicle (O) or $6 \mathrm{nM}$ IL-1 $\alpha(\bullet)$, and subsequently labeled with $0.1 \mathrm{nM}^{125}$ I-PDGF-AA (left) or ${ }^{125} \mathrm{I}$-PDGF-BB (right) for $3 \mathrm{~h}$ at $4^{\circ} \mathrm{C}$, without or with $0.2-25 \mathrm{nM}$ unlabeled PDGF-AA or PDGF-BB. The samples were rinsed and extracted, and nonspecific binding (13-14\% of total binding), determined by incubation with $>100$-fold molar excess of unlabeled homologous ligand, was subtracted. Each data point is the average of three replicate samples which differed from each other by $10 \%$ or less. Results were analyzed by the method of Scatchard (see reference 51), and the lines shown were determined by linear regression analysis of all data points. Analogous results were obtained in three separate experiments.

${ }^{125}$ I-PDGF-BB (lanes 9 and 10), whereas unlabeled PDGF-BB blocked binding by both radioligands (lanes 6 and 7).

Binding profiles obtained from cultures pretreated with IL$1 \alpha$ demonstrated an increase in ${ }^{125}$ I-PDGF-AA binding at both binding sites ( $>200$ and $185 \mathrm{kD}$ ), but there was a relatively greater increase in its association within the complexes found at $185 \mathrm{kD}$ (Fig. 4, lane 3). Consistent with the data obtained from saturation binding studies, IL- $1 \alpha$ did not alter ${ }^{125}$ I-PDGFBB binding at either location (Fig. 4, lane 4). ${ }^{125}$ I-PDGF-AA was convincingly displaced by unlabeled PDGF-AA in both control and IL- $1 \alpha$ pretreated cultures (Fig. 5, lanes 2 and 5), whereas unlabeled PDGF-BB competed less well for ${ }^{125} \mathrm{I}-$ PDGF-AA binding after IL-1 $\alpha$ pretreatment (Fig. 5, lanes 3 and 6). Furthermore, consistent with total PDGF-BB binding and cross-linking studies, competition by unlabeled PDGF-AA or PDGF-BB for ${ }^{125}$ I-PDGF-BB binding was not different in either situation (not shown). Similar increases in ${ }^{125}$ I-PDGFAA binding occurred after TNF- $\alpha$ pretreatment (Fig. 6, lane 2), while TGF- $\beta 1$ pretreatment completely reduced ${ }^{125}$ I-PDGFAA binding throughout the polyacrylamide gel profile (Fig. 6, 


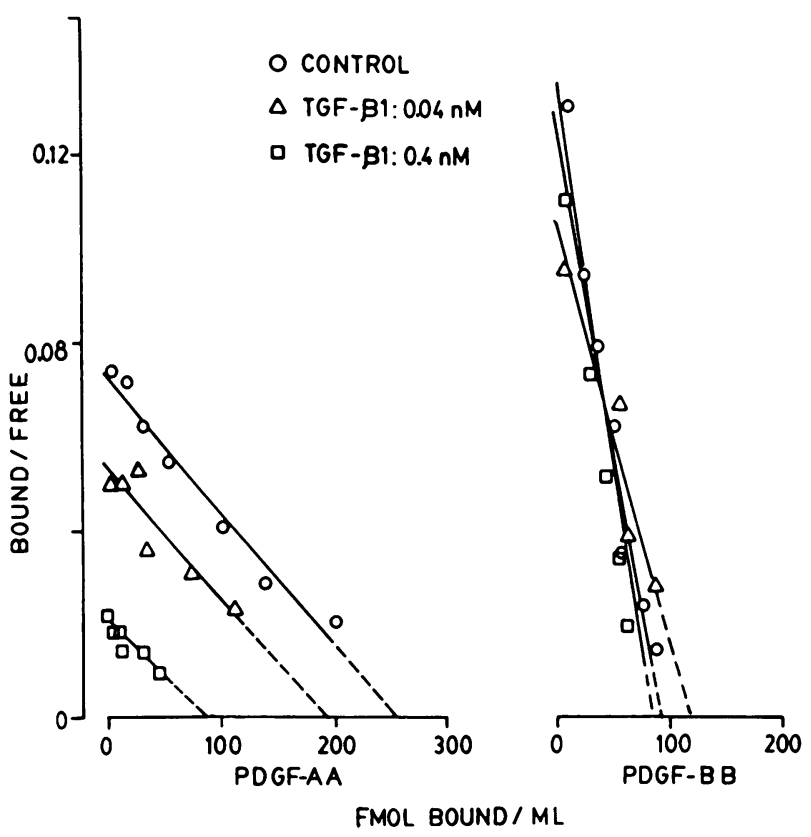

Figure 3. Effect of TGF- $\beta$ on PDGF-AA and PDGF-BB binding in osteoblast-enriched cultures from fetal rat bone. Serum-deprived confluent cultures were pretreated for $20 \mathrm{~h}$ with vehicle (o), $0.04 \mathrm{nM}$ TGF- $\beta 1(\Delta)$, or $0.4 \mathrm{nM}$ TGF- $\beta 1$ ( $\square$ ), and subsequently labeled with $0.1 \mathrm{nM}^{125}$ I-PDGF-AA (left) or ${ }^{125}$ I-PDGF-BB (right) for $3 \mathrm{~h}$ at $4^{\circ} \mathrm{C}$, without or with $0.2-10 \mathrm{nM}$ unlabeled PDGF-AA or PDGF-BB. The cultures were rinsed and extracted, and nonspecific binding was subtracted, as in Fig. 2. Each data point is the average of three replicate samples which differed from each other by $10 \%$ or less. Results were analyzed by the method of Scatchard (see reference 51), and the lines shown were determined by linear regression analysis of all data points. Analogous results were obtained in two separate experiments.

lane 3). Like IL-1 $\alpha$, TNF- $\alpha$ and TGF- $\beta 1$ did not alter the ${ }^{125}$ IPDGF-BB binding profile (not shown).

To address whether the increased level of PDGF-AA binding in IL- $1 \alpha$ - and TNF- $\alpha$-pretreated cultures resulted wholly from an increase in new receptor synthesis, analogous studies were performed in the presence of cycloheximide to inhibit translation during the pretreatment periods. Initial studies showed that the net levels of PDGF-AA and PDGF-BB binding did not change significantly in untreated cultures when assayed at various points throughout $48 \mathrm{~h}$ in serum-free medium (not shown). In the presence of cycloheximide at $2 \mu \mathrm{M}$, which is sufficient to decrease protein synthesis by $\sim 85 \%$ in this culture model (43), PDGF-AA binding was rapidly reduced, with an $\sim 30 \%$ decrease in $2.5 \mathrm{~h}$. By $24 \mathrm{~h}$, there was an $80-90 \%$ loss in PDGF-AA binding which was not further reduced at later times. Parallel studies with PDGF-BB showed a much slower loss in binding site turnover (Table V). While pretreatment with IL- $1 \alpha$ enhanced total PDGF-AA binding in the absence of cycloheximide, an $\sim 1.6-2$-fold higher level of binding persisted in cultures pretreated with both IL-1 $\alpha$ and cycloheximide, by comparison to cycloheximide alone. In contrast, IL$1 \alpha$ did not enhance PDGF-BB binding in the absence or presence of cycloheximide (Fig. 7 and Table VI).

Analogous studies were performed in cultures treated with $1.3 \mu \mathrm{M} \alpha$-amanitin to inhibit RNA polymerase II-dependent mRNA-specific transcription (44). These results demonstrated that $\alpha$-amanitin produced a somewhat slower decay in PDGF-

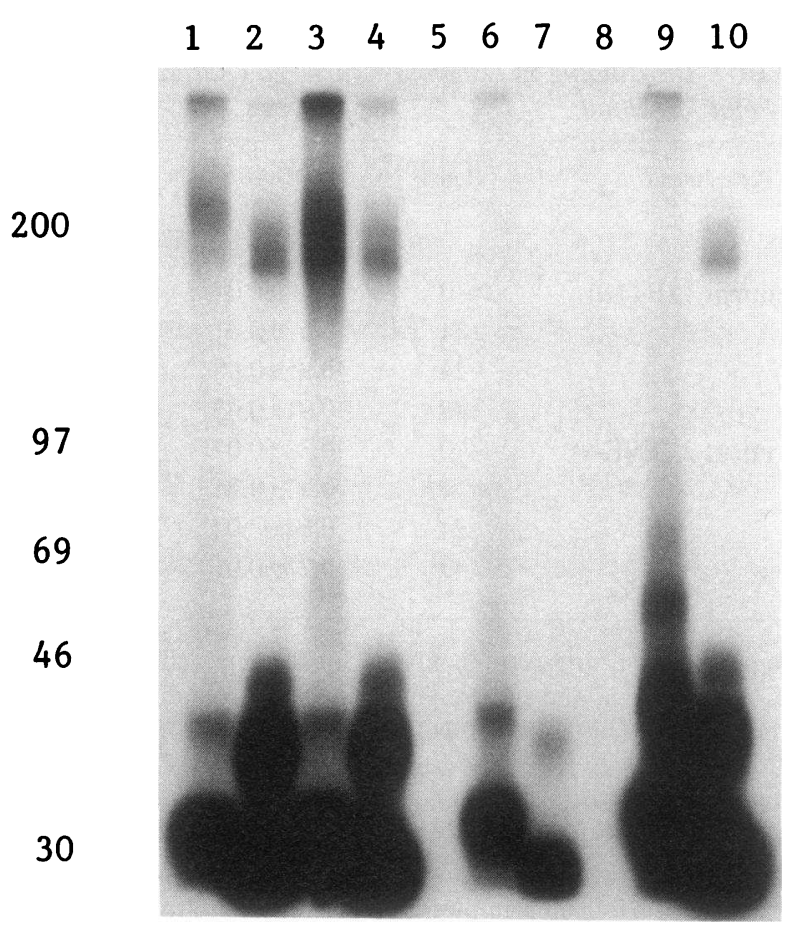

Figure 4. Effect of IL-1 $\alpha$ on PDGF-AA and PDGF-BB binding site distribution in osteoblast-enriched cultures from fetal rat bone. Serum deprived confluent cultures were incubated for $20 \mathrm{~h}$ without (lanes $1,2,6,7,9$, and 10) or with (lanes 3 and 4) $2 \mathrm{nM} \mathrm{IL-1} \alpha$, and labeled for $3 \mathrm{~h}$ at $4^{\circ} \mathrm{C}$ with $0.25 \mathrm{nM}^{125}$ I-PDGF-AA (lanes $1,3,6$, and 9) or $0.25 \mathrm{nM}^{125}$ I-PDGF-BB (lanes 2, 4, 7, and 10) in the absence (lanes 1-4) or presence of $2.5 \mathrm{nM}$ unlabeled PDGF-AA (lanes 9 and 10) or $2.5 \mathrm{nM}$ unlabeled PDGF-BB (lanes 6 and 7). No samples were loaded into lanes 5 and 8 . The cultures were rinsed, cross-linked with DSS, and fractionated by electrophoresis through a $5-15 \%$ polyacrylamide gel, and ${ }^{125}$ I-labeled binding complexes were displayed by autoradiography, as described in Methods. Numbers on the left $\left(\times 10^{-3}\right)$ show positions of migration by standards in the range of $M_{\mathrm{r}} 30,000$ $200,000 \mathrm{D}$. Analogous changes in the binding patterns shown were observed in three separate experiments.

AA binding relative to that in cycloheximide-treated cultures, whereas decreases in PDGF-BB binding were approximately equivalent after treatment with either inhibitor. IL- $1 \alpha$ also enhanced PDGF-AA binding in $\alpha$-amanitin-treated cultures above the levels observed with the toxin alone, but did not augment PDGF-BB binding in either situation (Fig. 8 and Table 6). Similar results were obtained in cultures pretreated with either IL- $1 \alpha$ or TNF- $\alpha$ and each metabolic inhibitor (Table VI).

\section{Discussion}

Earlier work in several model systems, including osteoblastenriched cultures from fetal rat bone, revealed that the maximal mitogenic potency of PDGF-AA, PDGF-AB, and PDGF$B B$ depends on the presence of PDGF-B subunits $(4,7-11)$. In some cultures this effect appears to result from the existence of independent PDGF- $\alpha$ and PDGF- $\beta$ receptor subunits that dimerize in response to ligand binding, and the different affinities of each receptor subunit for the individual ligand subunit chains (14). Although PDGF- $\alpha$ receptor subunits bind either PDGF-A or PDGF-B chains (and therefore all dimeric PDGF 


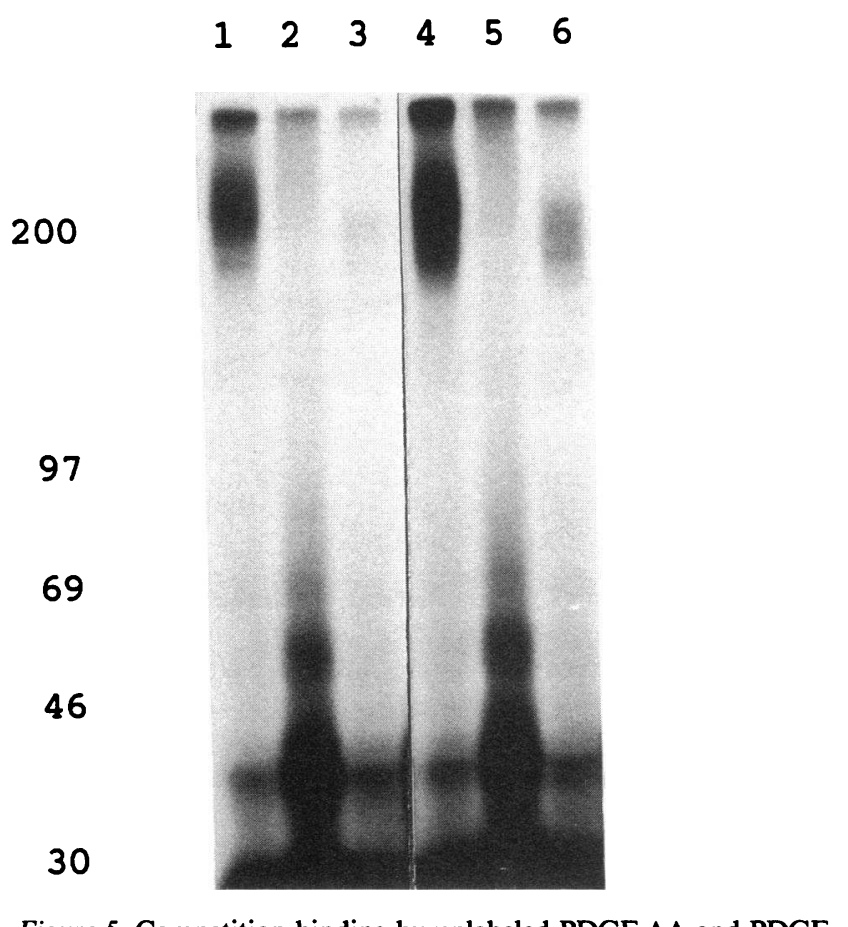

Figure 5. Competition binding by unlabeled PDGF-AA and PDGFBB for radiolabeled PDGF-AA binding in untreated and IL- $1 \alpha$-pretreated osteoblast-enriched cultures from fetal rat bone. Serum deprived confluent cultures were incubated for $20 \mathrm{~h}$ without (lanes 1-3) or with $2 \mathrm{nM} \mathrm{IL-} \alpha \alpha$ (lanes 4-6), and labeled for $3 \mathrm{~h}$ at $4^{\circ} \mathrm{C}$ with 0.25 $\mathrm{nM}{ }^{125} \mathrm{I}$-PDGF-AA in the absence (lanes 1 and 4 ) or presence of 2.5 nM unlabeled PDGF-AA (lanes 2 and 5) or $2.5 \mathrm{nM}$ unlabeled PDGF-BB (lanes 3 and 6). The cultures were rinsed, cross-linked with DSS, fractionated by electrophoresis through a $5-15 \%$ polyacrylamide gel, and ${ }^{125} \mathrm{I}$-labeled binding complexes were displayed by autoradiography, as described in Methods. Numbers on the left $\left(\times 10^{-3}\right)$ show positions of migration by standards in the range of $M_{\mathrm{r}} 30,000$ $200,000 \mathrm{D}$.

isoforms), PDGF- $\beta$ receptor subunits preferentially bind PDGF-B chains $(8,13,14)$. Furthermore, occupancy of PDGF- $\beta$ receptor subunits is consistent with maximal cellular responsiveness $(10,11,13-15)$.

The present studies demonstrate that in osteoblastenriched cultures from fetal rat bone, the modest mitogenic effect of PDGF-AA, by comparison to other PDGF isoforms, is enhanced by preexposure to IL- $1 \alpha$ or TNF- $\alpha$. This result coincides with a specific increase in PDGF-AA binding site capacity, independent of a change in PDGF-BB binding. Increased PDGF-AA binding is not completely accounted for by the moderate effects of IL-1 $\alpha$ or TNF- $\alpha$ on cell replication (this report and reference 34 ), and does not seem nonspecific since, similar to results with murine 3 T3 fibroblasts (45), TGF- $\beta 1$ specifically decreases PDGF-AA binding in the osteoblast-enriched cultures, and a variety of other agents are without effect in this regard.

Previous studies in the osteoblast-enriched cultures that are used in this report reveal a pattern of PDGF isoform cross-receptor binding in which PDGF-AA does not effectively compete for ${ }^{125}$ I-PDGF-BB binding, while ${ }^{125}$ I-PDGF-AA and ${ }^{125}$ IPDGF-BB binding are each displaced by PDGF-BB (11). This result is consistent with other culture models $(8,13,14)$, and suggests that these cells express a conventional PDGF- $\alpha$ and PDGF- $\beta$ receptor recognition system. As seen previously in
200

97

69

46

30<smiles>[101InH]</smiles>

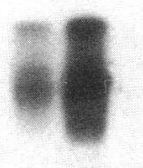

this and several other culture models, ${ }^{125}$ I-PDGF-BB-labeled complexes migrate on polyacrylamide gels at $185 \mathrm{kD}(8,18)$. However, the relatively high migration of the predominant ${ }^{125} \mathrm{I}$ PDGF-AA-labeled complex found at $>200 \mathrm{kD}$ in our unstimulated cultures suggests differences between the PDGFAA binding sites on fetal rat osteoblasts and the $170-\mathrm{kD}$ PDGF-AA-labeled complexes seen in human glioma and foreskin fibroblast-derived cultures $(8,12,18)$. The $>200-\mathrm{kD}$ co.nplexes have appeared consistently in our studies using four separate radiolabeled PDGF-AA preparations, two cross-linking reagents (DSS and $\mathrm{BS}^{3}$ ), and at DSS concentrations of $0.1-0.5$ $\mathrm{mM}$. Current attempts to characterize these fetal rat cell binding sites with anti-human PDGF receptor antibodies have not shown sufficient cross reactivity to resolve whether they are homologues of PDGF receptor subunits found in other culture models. Furthermore, the $>200-\mathrm{kD}$ complexes may be particular only to certain tissues, or to cells at particular states of differ-

Table V. PDGF-AA and PDGF-BB Binding in the Presence of Cycloheximide in Osteoblast-enriched Cultures from Fetal Rat Bone

\begin{tabular}{ccc}
\hline Hours & PDGF-AA & PDGF-BB \\
\hline \multicolumn{3}{c}{ fmol bound $/ \mathrm{cm}^{2}$} \\
0 & $0.47 \pm 0.01$ & $2.0 \pm 0.20$ \\
2.5 & $0.32 \pm 0.01$ & $1.8 \pm 0.06$ \\
21.5 & $0.04 \pm 0.01$ & $1.9 \pm 0.03$ \\
45 & $0.10 \pm 0.01$ & $1.9 \pm 0.03$ \\
\hline
\end{tabular}

Serum-deprived cultures were incubated for the times shown with 2 $\mu \mathrm{M}$ cycloheximide and subsequently incubated in binding medium supplemented with either ${ }^{125}$ I-PDGF-AA or ${ }^{125}$ I-PDGF-BB for $3 \mathrm{~h}$ at $4^{\circ} \mathrm{C}$. The cultures wre rinsed four times with cold buffer and extracted with $1 \%$ Triton X-100, and the amount of bound label was measured in a gamma spectrometer. The data were calculated by reference to culture size $\left(2 \mathrm{~cm}^{2}\right)$ and radioligand concentration $(0.1 \mathrm{nM})$, are given as mean $\pm \mathrm{SE}$ of triplicate samples, and are representative of three separate experiments. 


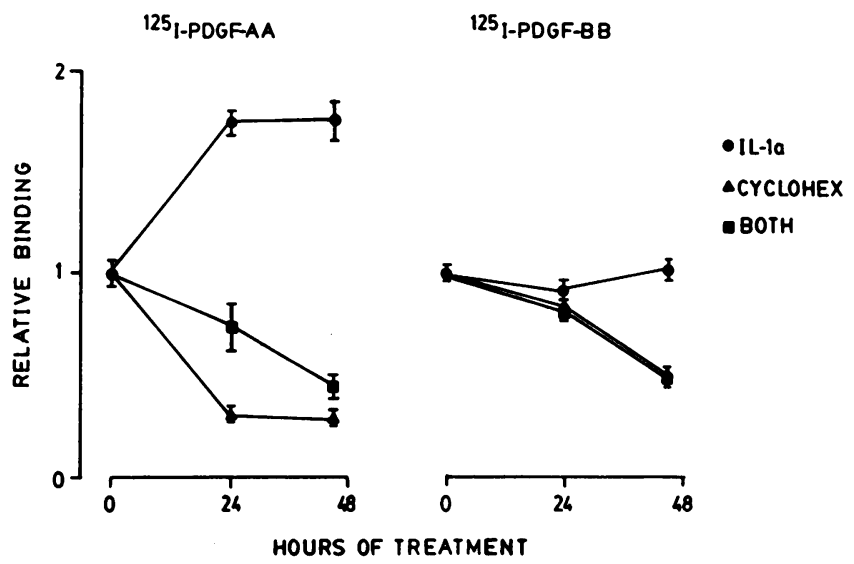

Figure 7. Effect of cycloheximide on PDGF-AA and PDGF-BB binding in IL-1 $\alpha$-treated osteoblast-enriched cultures from fetal rat bone. Serum-deprived confluent cell cultures were incubated for the times indicated with $6 \mathrm{nM}$ IL-1 $\alpha(\bullet), 2 \mu \mathrm{M}$ cycloheximide ( $\Delta$ ) or both ( $\bullet$ ), after which they were labeled for $3 \mathrm{~h}$ at $4^{\circ} \mathrm{C}$ with $0.1 \mathrm{nM}{ }^{125}$ I-PDGFAA (left) or $0.1 \mathrm{nM}^{125} \mathrm{I}-\mathrm{PDGF}-\mathrm{BB}$ (right). The cultures were rinsed four times with cold buffer, extracted with $1 \%$ Triton X-100, and the amount of bound label was measured in a gamma spectrometer. Data are given as mean $\pm \mathrm{SE}$ of triplicate samples, and are representative of three separate experiments. Results were converted to show binding levels relative to control (no pretreatments) in order to compare directly the effects of pretreatment on PDGF-AA and PDGF-BB binding. In the experiment shown, control PDGF-AA and PDGF-BB binding levels were $1.4 \pm 0.06$ and $4.0 \pm 0.1 \mathrm{fmol} / 2-\mathrm{cm}^{2}$ culture, respectively.

entiation or metabolic activity, since they were not observed in human MG-63 osteosarcoma cultures assessed under the same conditions (M. Centrella, unpublished results). Although these complexes may represent distinct binding sites or modified ver-

Table VI. Effects of IL-1 $\alpha$ and TNF- $\alpha$ on PDGF-AA and PDGF$B B$ Binding in the Presence of Cycloheximide or $\alpha$-Amanitin in Osteoblast-enriched Cultures from Fetal Rat Bone

\begin{tabular}{lccc}
\hline Pretreatment & Control & Cycloheximide & $\alpha$-amanitin \\
\hline & & $f m o l / \mathrm{cm}^{2}$ & \\
PDGF-AA & & & \\
None & $0.35 \pm 0.02$ & $0.13 \pm 0.01$ & $0.27 \pm 0.02$ \\
IL-1 $\alpha$ & $0.58 \pm 0.02$ & $0.26 \pm 0.04$ & $0.44 \pm 0.03$ \\
TNF- $\alpha$ & $0.66 \pm 0.02$ & $0.24 \pm 0.01$ & $0.55 \pm 0.02$ \\
PDGF-BB & & & \\
None & $4.4 \pm 0.1$ & $3.7 \pm 0.07$ & $3.8 \pm 0.13$ \\
IL-1 $\alpha$ & $4.1 \pm 0.1$ & $3.6 \pm 0.07$ & $3.7 \pm 0.18$ \\
TNF- $\alpha$ & $3.9 \pm 0.1$ & $3.3 \pm 0.08$ & $3.1 \pm 0.13$ \\
\end{tabular}

Serum-deprived cultures were incubated for $24 \mathrm{~h}$ without or with 2.0 $\mathrm{nM}$ IL- $1 \alpha$ or TNF- $\alpha$ in the absence or presence of $2 \mu \mathrm{M}$ cycloheximide or $1.3 \mu \mathrm{M} \alpha$-amanitin, as indicated, and subsequently incubated in binding medium supplemented with either ${ }^{125}$ I-PDGF-AA or ${ }^{125} \mathrm{I}-\mathrm{PDGF}-\mathrm{BB}$ for $3 \mathrm{~h}$ at $4^{\circ} \mathrm{C}$. The cultures were rinsed four times with cold buffer and extracted with $1 \%$ Triton X-100, and the amount of bound label was measured in a gamma spectrometer. The data were calculated by reference to culture size $\left(2 \mathrm{~cm}^{2}\right)$ and radioligand concentration $(0.1 \mathrm{nM})$, are given as mean \pm SE of triplicate samples, and are representative of two separate experiments.

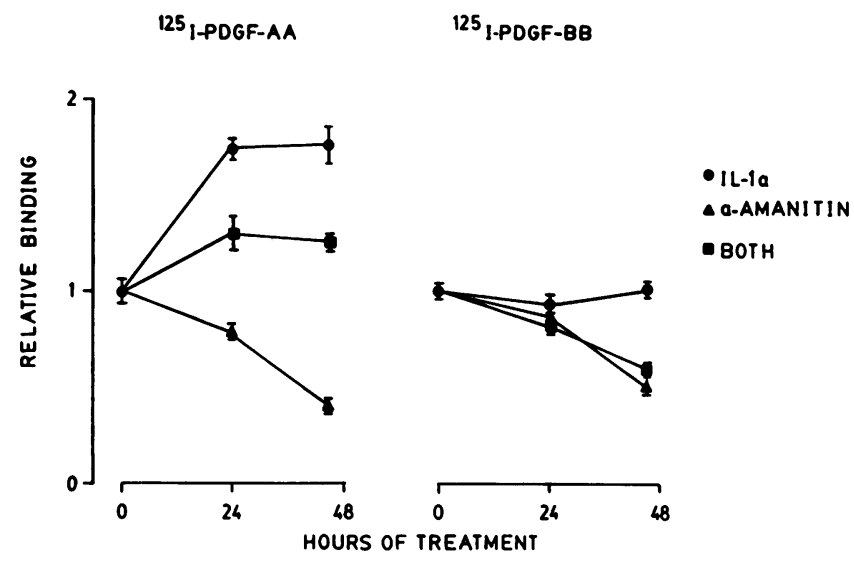

Figure 8. Effect of $\alpha$-amanitin on PDGF-AA and PDGF-BB binding in IL-1 $\alpha$-treated osteoblast-enriched cultures from fetal rat bone. Serum-deprived confluent cell cultures were incubated for the times indicated with $6 \mathrm{nM} \mathrm{IL-1} \alpha(\bullet), 1.3 \mu \mathrm{M} \alpha$-amanitin ( $\Delta$ ) or both ( $(\square)$, after which they were labeled for $3 \mathrm{~h}$ at $4^{\circ} \mathrm{C}$ with $0.1 \mathrm{nM}{ }^{125}$ I-PDGFAA (left) or $0.1 \mathrm{nM}^{125} \mathrm{I}$-PDGF-BB (right). The cultures were rinsed four times with cold buffer, extracted with $1 \%$ Triton X-100, and the amount of bound label was measured in a gamma spectrometer. Data are given as mean $\pm \mathrm{SE}$ of triplicate samples, and are representative of three separate experiments. Results were converted to demonstrate PDGF-AA and PDGF-BB binding relative to control (no pretreatments), as in Fig. 7.

sions of conventional PDGF receptors, they do not seem large enough to be analogues of the high molecular mass complexes containing two intact PDGF receptor dimers, induced by ligand binding, in murine NIH 3T3 fibroblast cultures (46). A greater apparent molecular mass could indicate differences in glycosylation, alterations in proteolytic processing, or the presence of intracellular proteins that also receptor-associate after ligand binding, as previously demonstrated for PDGF- $\beta$ receptors using murine $3 \mathrm{~T} 3$ cells (47).

Because PDGF-A and PDGF-B chains each bind to the PDGF- $\alpha$ receptor subunit, and because we find an increase in PDGF-AA activity and binding in IL- $1 \alpha$ - and TNF- $\alpha$-pretreated cultures in the virtual absence of an increase in PDGF$\mathrm{BB}$ activity and binding, this effect is unlikely to result from a simple increase in PDGF- $\alpha$ receptor subunit synthesis. This dichotomy can be reconciled in part by the banding profiles obtained by polyacrylamide gel electrophoresis and autoradiography. IL- $1 \alpha$ or TNF- $\alpha$ can specifically increase ${ }^{125}$ I-PDGF-AA binding within both $>200$ - and $185-\mathrm{kD}$ complexes on fetal rat osteoblasts, but this effect is most notable at the 185-kD sites that co-migrate with those labeled with ${ }^{125}$ I-PDGF-BB. Therefore, preferential PDGF-AA binding within complexes that normally favor PDGF-BB could account at least in part for the relative increase in PDGF-AA activity to essentially the level produced by PDGF-BB. Alternately, the increase in ${ }^{125} \mathrm{I}$ PDGF-AA-labeled complexes at $185 \mathrm{kD}$ after IL- $1 \alpha$ or TNF- $\alpha$ treatment could represent changes in the receptor subunits contained in the $>200-\mathrm{kD}$ complexes resulting in reduced molecular mass, but increased ligand binding and signal transduction.

In addition, whereas net PDGF-AA binding is relatively constant in quiescent osteoblast-enriched cultures from fetal rat bone, it decreases rapidly with cycloheximide treatment, suggesting that basal PDGF-AA binding sites are synthesized in 
equilibrium with those lost to down-regulation or proteolysis. Although PDGF-AA binding sites are more sensitive to transcription and translation inhibitors than those for PDGF-BB in these cultures, IL- $1 \alpha$ and TNF- $\alpha$ continue to enhance PDGFAA binding in the absence of new receptor synthesis. Therefore, the stimulatory effects by these cytokines that we note cannot wholly be explained by an increase in PDGF receptor mRNA synthesis or stability. Although changes in receptor turnover rate may occur in pretreated cultures, a biochemical alteration in the receptors themselves, or allosteric changes that specifically increase recognition of PDGF-A subunits, might also account in part for the increased level of PDGF-AA binding, independent of that for PDGF-BB, observed in the present studies. This possibility is further emphasized in competition binding studies between ${ }^{125}$ I-PDGF-AA and unlabeled PDGFs. Although unlabeled PDGF-AA was similarly competent in this regard in either control or IL- $1 \alpha$-pretreated cultures, competition by unlabeled PDGF-BB was somewhat reduced after IL- $\alpha$ treatment. A mechanism of this sort could permit relatively rapid changes in receptor-mediated signal transduction, and provide protection against constitutive autostimulation. In this regard, increased PDGF-AA binding is noted as soon as $4 \mathrm{~h}$ after IL- $1 \alpha$ or TNF- $\alpha$ pretreatment. A precise balance is further suggested by the rapid turnover of PDGF-AA-specific binding sites in unpretreated cultures, although binding at this site alone may not be sufficient for maximal biochemical signaling.

A recent report of studies performed with continuously cultured murine osteoblast-like cells (MC3T3-E1) also demonstrates that IL- $1 \alpha$ increases PDGF-AA effects, and suggests that this occurs by way of increased PDGF- $\alpha$ receptor subunit synthesis (48). However, in those studies, IL- $1 \alpha$ pretreatment increased both PDGF-AA and PDGF-BB activity to nearly the same extent, whereas only PDGF-AA activity and binding is enhanced in the fetal rat bone-derived cell culture model used in our studies. Nevertheless, the metabolic inhibitor studies that we report do not discount the possibility that continual or elevated PDGF- $\alpha$ receptor synthesis, as detected in MC3T3-E1 cells, may be important for certain maximal biological responses, but they do indicate that the response to IL- $1 \alpha$ and TNF- $\alpha$ may be somewhat more complex than previously suspected. Alterations in PDGF-AA binding by the various treatments used in these studies also may be specific to certain tissues, or to cells from skeletal tissue at particular stages of development, and different effects may be found in other cells or culture models. In this regard, our present results may only apply to osteoblasts within particular anatomical regions within bone, or may not be evident in bone tissue from some mature organisms or in fully differentiated osteoblasts.

Production of only PDGF-A ligand subunits by osteoblasts $(6,19)$ further indicates an important role for this isoform in the local control of bone cell activity. It is notable that three factors produced by activated macrophages (IL- $1 \alpha$, TNF- $\alpha$, and TGF- $\beta$ ) share an ability to alter PDGF-AA, and not PDGF-BB binding in fetal bone cell cultures. This may indicate that other PDGF isoforms which are found in serum (3, 49) could be important in the systemic regulation of bone cell activity, but that specific and rapid changes at the local level may be restricted to PDGF-AA. An increase in osteoblast activity is noted histologically after the reversal phase of bone remodeling, during which there is an appearance of macrophages (20), and this may occur as a result of the interacting effects of macrophage-derived IL- $1 \alpha$ or TNF- $\alpha$ with osteoblast-derived
PDGF-AA. Furthermore, macrophages accumulate within the area of inflammation after wounding (50), and rapid increases in osteoblastic responses needed for fracture healing may be augmented by the synergistic activities between these agents and PDGF-AA, as observed in the present studies. Therefore, it appears that at least in some osteoblast populations, there is a highly developed mechanism for increasing PDGF-AA effectiveness, independent of an increase in ligand or receptor synthesis or release from binding proteins (as occurs with TGF- $\beta$ and the insulin-like growth factors). It is also notable that, unlike the stimulatory effects of IL- $1 \alpha$ and TNF- $\alpha$, TGF- $\beta 1$ specifically decreases PDGF-AA binding in this culture model, but that no biological response has yet been correlated with this effect. By itself, TGF- $\beta 1$ is a strong biphasic mitogen in the osteoblast-enriched cell culture system used in these studies $(25,42,43)$. Consequently, its potency in this system makes it difficult to assess the interacting effects of TGF- $\beta 1$ and the PDGFs using the pretreatment protocol developed for the present experiments.

In summary, the macrophage-derived factors IL- $1 \alpha$ and TNF- $\alpha$ specifically increase PDGF-AA binding and activity in osteoblast-enriched cultures from fetal rat bone. Although increased PDGF-AA binding occurs within complexes that seem normally to favor either PDGF-A or PDGF-B subunits in unstimulated cultures, there is a striking increase at $185 \mathrm{kD}$, which co-migrates with PDGF-BB binding complexes, consistent with the premise that binding within the $185-\mathrm{kD}$ complex is necessary for maximal PDGF activity in bone cells (11). These studies continue to implicate the fine balance that exists among multiple factors in the control of bone cell activity, and suggest that cellular interactions, by way of specific local growth factors, may precisely regulate the complex processes of bone turnover and repair.

\section{Acknowledgments}

The authors are grateful for critical discussions with Dr. W. Jackson Pledger (Vanderbilt University, Nashville, TN) and Drs. Ronald A. Seifert and Daniel F. Bowen-Pope (University of Washington, Seattle, WA), and the expert assistance of Sandra Casinghino, Bari Gabbitas, Sheila Rydziel, and Chwee Tiong throughout these studies.

This work was supported by National Institutes of Health grants AR-39201 and AR-21707, and Saint Francis Hospital and Medical Center.

\section{References}

1. Deuel, T. F. 1987. Polypeptide growth factors: roles in normal and abnormal cell growth. Annu. Rev. Cell Biol. 3:443-492.

2. Heldin, C. -H., and B. Westermark. 1989. Platelet-derived growth factors: a family of isoforms that bind to two distinct receptors. Br. Med. Bull. 45:453-464.

3. Bowen-Pope, D. F., C. E. Hart, and R. A. Seifert. 1989. Sera and conditioned media contain different isoforms of platelet-derived growth factor (PDGF) which bind to different classes of PDGF receptor. J. Biol. Chem. 264:2502-2508.

4. Raines, E. W., S. K. Dower, and R. Ross. 1989. Interleukin-1 mitogenic activity for fibroblasts and smooth muscle cells is due to PDGF-AA. Science (Wash. DC). 243:393-396.

5. Noble, M., K. Murray, P. Stroobant, M. D. Waterfield, and P. Riddle. 1988. Platelet-derived growth factor promotes division and motility and inhibits premature differentiation of the oligodendrocyte/type-2 astrocyte progenitor cell. Nature (Lond.). 333:560-562.

6. Graves, D. T., A. Valentin-Opran, R. Delgado, A. J. Valente, G. Mundy, and J. Piche. 1989. The potential role of platelet-derived growth factor as an autocrine or paracrine factor for human bone cells. Connect. Tissue Res. 23:209218.

7. Beckman, M. P., C. Betscholtz, C. -H. Heldin, B. Westermark, E. DeMarco, P. P. DiFiore, K. C. Robbins, and S. A. Aaronson. 1988. Comparison of biologi- 
cal properties and transforming potential of human PDGF-A and PDGF-B chains. Science (Wash. DC). 241:1346-1349.

8. Heldin, C. -H., G. Backstrom, A. Ostman, A. Hammacher, L. Ronnstrand, K. Rubin, M. Nister, and B. Westermark. 1988. Binding of different dimeric forms of PDGF to human fibroblasts: evidence for two separate receptor types. EMBO (Eur. Mol. Biol. Organ.) J. 7:1387-1393.

9. Clark, R. A. F., J. M. Folkvord, C. E. Hart, M. J. Murray, and J. M. McPherson. 1989. Platelet isoforms of platelet-derived growth factor stimulate fibroblasts to contract collagen matrices. J. Clin. Invest. 84:1036-1040.

10. Matsui, T., J. H. Pierce, T. P. Fleming, J. S. Greenberger, W. J. LaRochelle, M. Ruggiero, and S. A. Aaronson. 1989. Independent expression of hu$\operatorname{man} \alpha$ or $\beta$ platelet-derived growth factor receptor $\mathrm{CDNAs}$ in a naive hematopoietic cell leads to functional coupling with mitogenic and chemotactic signaling pathways. Proc. Natl. Acad. Sci. USA. 86:8314-8318.

11. Centrella, M., T. L. McCarthy, W. F. Kusmik, and E. Canalis. 1991. Relative binding and biochemical effects of heterodimeric and homodimeric isoforms of platelet-derived growth factor in osteoblast-enriched cultures from fetal rat bone. J. Cell. Physiol. 147:420-426.

12. Claesson-Welsh, L., A. Hammacher, B. Westermark, C. -H. Heldin, and M. Nister. 1989. Identification and structural analysis of the A type receptor for platelet-derived growth factor. J. Biol. Chem. 264:1742-1747.

13. Hart, C. E., J. W. Forstrom, J. D. Kelly, R. A. Seifert, R. A. Smith, R. Ross, M. J. Murray, and D. F. Bowen-Pope. 1988. Two classes of PDGF receptor recognize different isoforms of PDGF. Science (Wash. DC). 240:1529-1531.

14. Seifert, R. A., C. E. Hart, P. E. Phillips, J. W. Forstrom, R. Ross, M. J. Murray, and D. F. Bowen-Pope. 1989. Two different subunits associate to create isoform specific platelet-derived growth factor receptors. J. Biol. Chem. 264:8771-8778.

15. Escobedo, J. A., S. Navantkasatussas, L. S. Cousens, S. R. Coughlin, G. I. Bell, and L. T. Williams. 1988. A common PDGF receptor is activated by homodimeric A and B forms of PDGF. Science (Wash. DC). 240:1532-1534.

16. Vogel, A., E. Raines, B. Kariya, M. J. Rivest, and R. Ross. 1978. Coordinate control of $3 \mathrm{~T} 3$ cell proliferation by platelet-derived growth factor and plasma components. Proc. Natl. Acad. Sci. USA. 75:2810-2814.

17. Russell, W. E., J. J. VanWyk, and W. J. Pledger. 1984. Inhibition of mitogenic effects of plasma by a monoclonal antibody to somatomedin C. Proc. Natl. Acad. Sci. USA. 81:2389-2392.

18. Centrella, M., T. L. McCarthy, and E. Canalis. 1989. Platelet-derived growth factor enhances deoxyribonucleic acid and collagen synthesis in osteoblast-enriched cultures from fetal rat parietal bone. Endocrinology. 125:13-19.

19. Centrella, M., T. L. McCarthy, C. Ladd, and E. Canalis. 1990. Expression of platelet-derived growth factor (PDGF) and regulation of PDGF binding are both isoform specific in osteoblast-enriched cultures from fetal rat bone. J. Bone Miner. Res. 5:S86. (Abstr.)

20. Baron, R., A. Vignery, and M. Horowitz. 1984. Lymphocytes, macrophages, and the regulation of bone remodeling. In Bone and Mineral Research, Volume 2. W. Peck, editor. Elsevier Science Publishing Co., Inc., New York. 175-244.

21. Nathan, C. F. 1987. Secretory products of macrophages. J. Clin. Invest. 79:319-326

22. Old, L. J. 1985. Tumor necrosis factor (TNF). Science (Wash. DC). 230:630-632.

23. Assoian, R. K., B. E. Fleurdelys, H. C. Stevenson, P. J. Miller, D. K. Madtes, E. W. Raines, R. Ross, and M. B. Sporn. 1987. Expression and secretion of type $\beta$ transforming growth factor by activated human macrophages. Proc. Natl. Acad. Sci. USA. 84:6020-6024.

24. Dinarello, C. A. and N. Savage. 1989. Interleukin 1 and its receptor. Crit. Rev. Immunol. 9:1-20.

25. Centrella, M., T. L. McCarthy, and E. Canalis. 1987. Transforming growth factor beta is a bifunctional regulator of replication and collagen synthesis in osteoblast-enriched cell cultures from fetal rat calvariae. J. Biol. Chem. 262:2869-2874.

26. Hock, J. M., E. Canalis, and M. Centrella. 1990. Transforming growth factor $\beta$ (TGF $\beta$-1) stimulates bone matrix apposition and bone cell replication in cultured fetal rat calvariae. Endocrinology. 126:421-426.

27. Noda, M., and J. J. Camilliere. 1989. In vivo stimulation of bone formation by transforming growth factor- $\beta$. Endocrinology. 124:2992-2994.

28. Marcelli, C., A. J. Yates, and G. R. Mundy. 1990. In vivo effects of human recombinant transforming growth factor $\beta$ on bone turnover in normal mice. $J$. Bone Miner. Res. 5:1087-1096.

29. Lomri, A., and P. J. Marie. 1990. Bone cell responsiveness to transforming growth factor $\beta$, parathyroid hormone, and prostaglandin $E 2$ in normal and postmenopausal osteoporotic women. J. Bone Miner. Res. 5:1149-1155.

30. Canalis, E. 1986. Interleukin-1 has independent effects on deoxyribonucleic acid and collagen synthesis in cultures of rat calvariae. Endocrinology. 118:74-81.

31. Smith, D. D., M. Gowen, and G. R. Mundy. 1987. Effects of interferonand other cytokines on collagen synthesis in fetal rat bone cultures. Endocrinology. 120:2494-2499.

32. Canalis, E. 1987. Effects of tumor necrosis factor on bone formation in vitro. Endocrinology. 121:1596-1604.

33. Lorenzo, J. A., S. L. Sousa, and M. Centrella. 1988. Interleukin-1 in combination with transforming growth factor- $\alpha$ produces enhanced bone resorption in vitro. Endocrinology. 123:2194-2200.

34. Centrella, M., T. L. McCarthy, and E. Canalis. 1988. Tumor necrosis factor $\alpha$ inhibits collagen synthesis and alkaline phosphatase activity independently of its effect on deoxyribonucleic acid synthesis in osteoblast-enriched bone cell cultures. Endocrinology. 123:1442-1448.

35. Marusic, A., J. F. Kalinowski, J. R. Harrison, M. Centrella, L. G. Raisz, J. A. Lorenzo. 1991. Effects of transforming growth factor $\beta$ and interleukin $1 \alpha$ on prostaglandin synthesis in serum-deprived osteoblastic cells. J. Immunol. 146:2633-2638.

36. Circolo, A., G. F. Pierce, Y. Katz, and R. C. Strunk. 1990. Antiinflammatory effects of polypeptide growth factors: platelet-derived growth factor, epidermal growth factor, and fibroblast growth factor inhibit the cytokine-induced expression of the alternative complement pathway activator factor B in human fibroblasts. J. Biol. Chem. 265:5066-5071.

37. Chiou, W. J., P. D. Bonin, P. K. Harris, D. B. Carter, and J. P. Singh. 1989. Platelet-derived growth factor induces interleukin-1 receptor gene expression in Balb/c 3T3 fibroblasts. J. Biol. Chem. 264:21442-21445.

38. Wong, G. L., and D. V. Cohn. 1975. Target cells in bone for parathormone and calcitonin are different: enrichment for each cell type by sequential digestion of mouse calvaria and selective adhesion to polymeric surfaces. Proc. Natl. Acad. Sci. USA. 72:3167-3171.

39. McCarthy, T. L., M. Centrella, and E. Canalis. 1988. Further biochemical and molecular characterization of primary rat parietal bone cell cultures. $J$. Bone Miner. Res. 3:401-408.

40. Kissane, J. M., and E. Robbins. 1958. The fluormetric measurement of deoxyribonucleic acid in animal tissues with special reference to the central nervous system. J. Biol. Chem. 233:184-188.

41. Laemmli, U. K. 1970. Cleavage of structural proteins during the assembly of the head of bacteriophage T4. Nature (Lond.). 227:680-685.

42. Centrella, M., T. L. McCarthy, and E. Canalis. 1987. Mitogenesis in feta rat bone cells simultaneously exposed to transforming growth factor $\beta$ and other growth regulators. FASEB (Fed. Am. Soc. Exp. Biol.) J. 1:312-317.

43. Centrella, M., T. L. McCarthy, and E. Canalis. 1991. Glucocorticoid regulation of transforming growth factor $\beta 1$ (TGF- $\beta 1$ ) activity and binding in osteoblast-enriched cultures from fetal rat bone. Mol. Cell. Biol. 11:4490-4496.

44. Adams, R. L. P., R. H. Burdon, A. M. Campbell, R. M. S. Smellie. 1976. The biosynthesis of RNA: transcription. In Davidson's The Biochemistry of the Nucleic Acids, 8th edition. Academic Press, Inc., New York. 318-358.

45. Gronwald, R. G. K., R. A. Seifert, and D. F. Bowen-Pope. 1989. Differential regulation of expression of two platelet-derived growth factor receptor subunits by transforming growth factor- $\beta$. J. Biol. Chem. 264:8120-8125.

46. Li, W., and J. Schlessinger. 1991. Platelet-derived growth factor (PDGF)induced disulfide linked dimerization of PDGF receptors in living cells. $\mathrm{Mol}$. Cell. Biol. 11:3756-3761.

47. Kaplan, D. R., D. K. Morrison, G. Wong, F. McCormick, and L. T. Williams. 1990. PDGF $\beta$ receptor stimulates tyrosine phosphorylation of GAP and association of GAP with a signaling complex. Cell. 61:125-133.

48. Tsukamoto, T., T. Matsui, H. Nakata, M. Ito, T. Natazuka, M. Fukase, and T. Fujita. 1991. Interleukin-1 enhances the response of osteoblasts to plateletderived growth factor through the $\alpha$ receptor-specific up-regulation. $J$. Biol. Chem. 266:10143-10147.

49. Hammacher, A., U. Hellman, A. Johnnsnson, A. Ostman, K. Gunnarsson, B. Westermark, A. Wasteson, and C. -H. Heldin. 1988. A major part of PDGF purified from human platelets is a heterodimer of one A chain and one B chain. J. Biol. Chem. 263:16493-16498.

50. Clark, R. A. F. 1988. Overview and general consideration of wound repair. In Molecular and Cellular Biology of Wound Repair. R. A. F. Clark and P. M. Henson, editors. Plenum Press, New York. 3-33.

51. Scatchard, G. 1949. The attraction of proteins for small molecules and ions. Ann. NY Acad. Sci. 51:660-672. 